\title{
التداخل اللغوي بين العربية و الهندو - أوربية - التأثير والتأثر -
}

\section{م . د صيدر كرم الله قاسم/ كلية الإمام الكاظم (ع) اللعلوم الإسلإمبة / واسط}

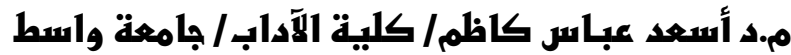

\section{هذف البحث}

يعد التداخل اللغوي بمفهومه العام احتكاك اللغات وتداخلها نتيجة التأثر والتأثثير بين العناصر اللغوية سواء على مستوى الفصيلة اللغويـة الواحدة أم

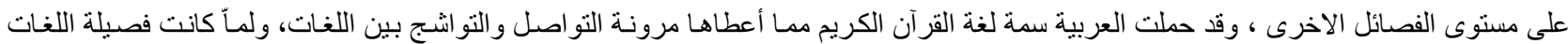

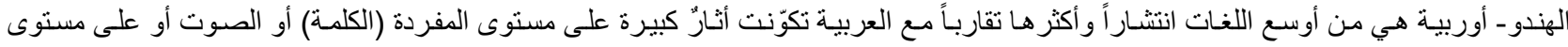
التركيب و الاسلوب، وقد حدى بالكثير من المفردات أو التر اكيب الصوتية أن تتناثر بين اللغات المتقابلة ، فضلاً عن محاولة جديدة لكثف أصول الكثير

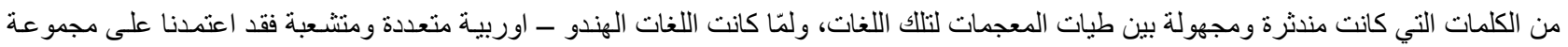
من اللغات التي اختلطت بالعربية بأسلوب مباشر سواء بالتجاور أو الغزوات والحروب و غير ها، أو باسلوب غير مباشر عن طريق التبادل العلمي والثقافي و التجاري.

تمثل اللغة في كل الثعوب مظهراً من مظاهر الحضارة والثقافة، فهي هوية الإنسان وتحضره، ولمّا كانت اللغـة اجتماعية النشأة و التكوين فهي تتأثر بما يعتريها من تقاليد وعادات المجنمعات الاخرى، ولعلّ ذلك ينعكس على أدائها في تحقيق وسائل التو اصل مع جميع اللغات، وبمـا امتلكته اللغـة العربية من تلك الخصـائص في تبنّيها وتأثير هـا على معظم لغات العالم فقد هيّات لنفسها ان تمتلك الصدارة ، فهي لغة القر آن الكريم ، ولعلّ ذلك جعلها تبسط مقوماتها في أقصى البلدان. ويعد تداخل اللغات أحد مظاهر التطور اللغوي ، الّا انّ تطور اللغـات بمأمن عن التأتر الخارجي ليس ممكناً ولا يمكن أن يتحقق مع جميع اللغات، بل العكس من ذلك، "فإنّ الأثر الذي يقع على لغة ما من لغات مجـاورة لها

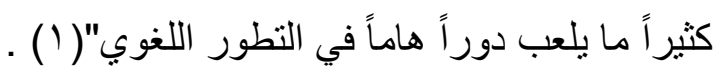

ولعلّ ما يميّز اللغة العربية في هذا المجال هو تداخلها مع كثير من لغات العـالم ، فقد أنشـار الباحث المسيحي

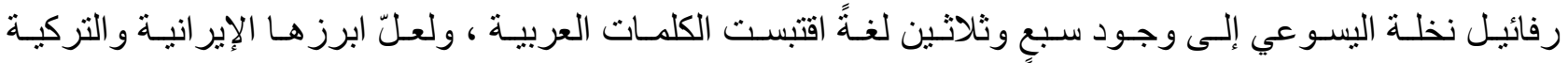
و الهندستانية * ، وإنّ قاموسهم اللغوي حافل بآلاف الكلمات العربية الأصل ، بحيث لا يكاد العثور على جملة طويلة في ولي تللك الألسن لا تحوي على عناصر عربية، ثم يذكر في موضع آخر بأن ما وجده في إنجيل القديس يوحنا وبخاصـة في

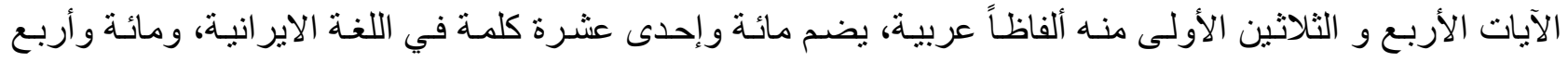

\section{كلمات في التركية، وثمانين كلمة في الهندستانية(r) .}

ويتمثل التداخل اللغوي في جوانب متعددة الّّ أنّ مـا يخص المفردات يعدّ أكثر أهميـة لا سيّما و إنّهـه يدخل في الجانب التركيبي للكلمة سواء أكان على مستوى الصـوت المفرد أم المقطع أم من بـاب التقابل النطقي للأصوات. و لا يمكن أن ننكر أهمية التداخل اللغوي على مستوى الاسلوب و المنهج وبخاصة في مجال الادب بصنفيه الثـعر و النثر ، وقد توضحت اكثر حينما تقلصت الدراسات اللغوية بمجال البحث في اللغة في العصر الاموي الذي يعد مرحلة تثبت الهوية اللغوية والقومية او ما يسمى نهاية عصر الاحتجـاج بعد ظهور اللحن واختلاط اللغات لينطلق الادب و الادبـاء في العصـر العباسـي و اتســاع اللغتين الفارسـية واليونانيـة، فقد اخذت الاسـاليب الادبيـة تظهـر بشـكل جلـي وحسبنا 
بشخصيتين مؤثرتين هما عبد الله بن المققع ، و أبو عثـان الجاحظ اللذان برّزا أثثار الأمم الأخرى ، وهكذا الحال في العصور المتقدمة بعد حملات الاحتلال وظهور مفهوم الانتداب مما هيأ الى مدر اس التجديد والحداثة .

وتكمن أهمية اللغة العربية في امتدادها الجغر افي على أثر الفتوحات الاسلامية التي امتدت من الثرق الى حدود

الصين ومن الغرب اللى بـلاد الأندلس ( اسبانيا والبرتغـال ) ، ومن الثـمال الى سفوح الاناضـول حتى الجنوب الى لى او اسط افريقيا ، فهي عانقت حضار ات العالم في آسيا وأوربا و أفريقيا ، ولعلّ هذا التناقح الحضـاري قد أفرز احتكاكاً

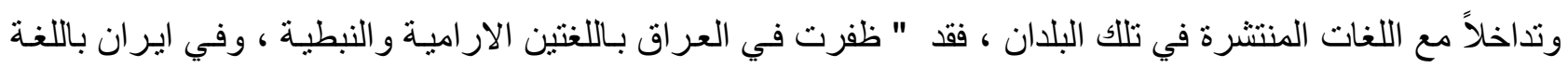

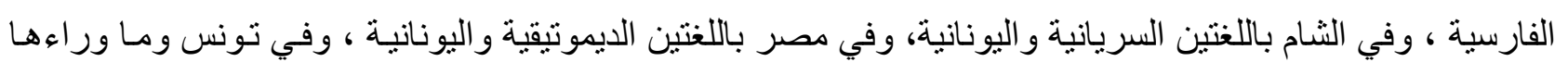

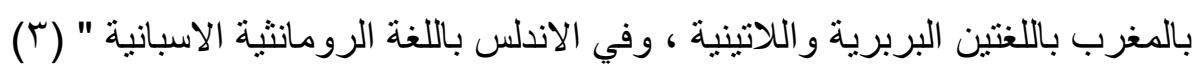

\section{التأثير والتأثر بين اللغات}

يمثل مفهوم التأثنير والتاثر بين اللغات قانوناً اجنماعياً انسانياً يحدث بين جميع اللغـات الحيّة التي تحتاج الى مـا تتميز به في ميدان التحضّر، ولعلّ الثـواهد حاضرة في ميدان كلّ لغة ، ومبدأ الاقتر اض يختلف بـاختلاف العلاقات القائمة بين متكلمي الثـعوب، فكلمـا قويت العلاقة بين الثـعبين زادت الروابط اللغويـة بينهمـا ، وبالتـالي تزداد فرص


بلاد الانكليز بعد الغزو، وكذلك اللغة اللاتينية اقترضت من اللغة الاغريقية ؛ لتجاور الثعبين اللاتيني والاغريقي ، ولعلّ تأثثر اللغة نفسها يختلف من مكان الى آخر، "فمـا اقتبسته ألمانية سويسر الهن من اللغـة الفرنسية لا يذكر بجانبـه مـا

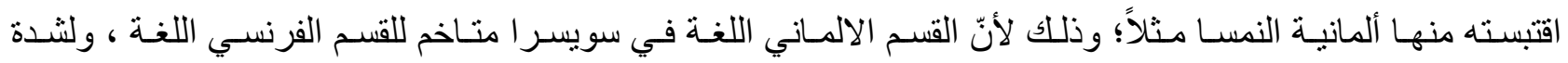
الاحتكالك بين سكان القسمين، على حين أنّ النمسا غير متاخمة لمنطقة فرنسية اللسان " (ع ) . أما العربية فقد تو افرت فيها شروط الاقتر اض اللغوي من كثير من اللغات سواء أكان بطريقة التجاور ام بغيره

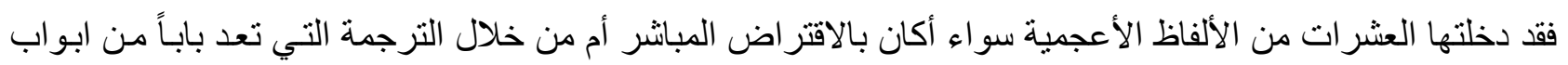

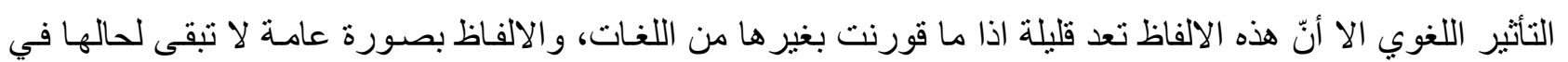

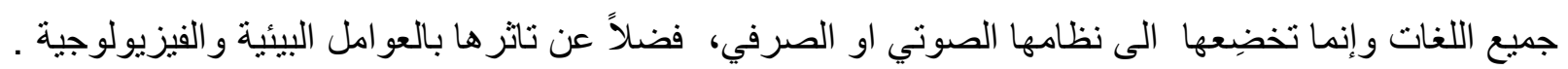
وقد وضـع أحد البـاحثين مفهوم التأثثر والتأثر بين اللغـات تحت بـاب الـتأثيل والترسيس ) ، و التأثيل ( Etymology)

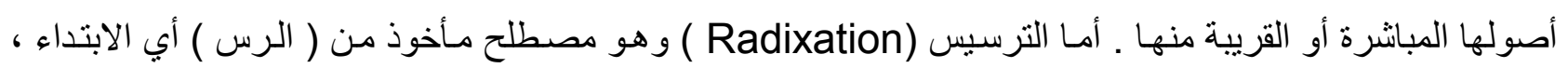
و المر اد به إرجاع اللفظة العربية أو الأعجمية إلى بداياتها الأولى أي مرحلة نشوء اللفظة وبداية نطقها .(0) و على الرغم من حداثة المصطلحين الا انهما يتناو لان الجانب التاريخي للفظة من حيث نشأتها والتطور الحاصل لها على مر التاريخ حتى يومنا هذا ، لكن ما يميز هذا المفهوم هو تتبع الالفاظ ليس على مستوى اللغنة التي تتنمي لها هذه اللفظة وانما مقارنتها مع اللغات الاخرى ومدى تاثر ها بتلك اللغة . 
وقد أشـار الباحـث إلى كثيـر مسن الألفـاظ إذ أرجعهـا إلى أصسولها العربيـة بعـما كانت متداولـة في اللغـات

الأوربية( (7). ويبدو أنّه حينما عرض لتلك الأمثلة الكثيرة كان قد وضع منهجاً محدداً في تحديد المصطلحين و إيجـاد الفوارق بينهما حينمـا وجد أنّ مفهوم التأصيل قد اصطبغ بالصبغة الأوربيـة بعد إن كان عربياً ، وأنّ الترسبس علم عربي محض استطاع أن يحدد بدايات الألفاظ ليس للعربية فحسب بل للكثير من الألفاظ في اللغات الأخرى . ويبدو أنّ هذا التحليل في تفسير التداخل اللغوي بين اللغات على أثر الظروف المحيطة وتأثر هـا باللغات الأخرى قد عمد إليه الكثير من الباحثين حينما يتناولون مفهوم الاخيل والمعرب في العربيـة إلا أنّ إيجاد المفاهيم والمصطلحات كان أكثر تميّز إ من أجل تحديد المنهج المتبع في بيان أصل الألفاظ ونشأتها وآلية الاستعمال بين اللغات. ويمكن إجمال أهم الأسباب و العوامل التي تؤدي إلى التأثثر والتأثر بين اللغات بما يلي :

ا ـ الاحتلال او الغزو بين الثتعوب ، و هذا يعود الى الصراع او الحروب ، اذ الهيمنة او الانتصـار في احتلال المنـاطق

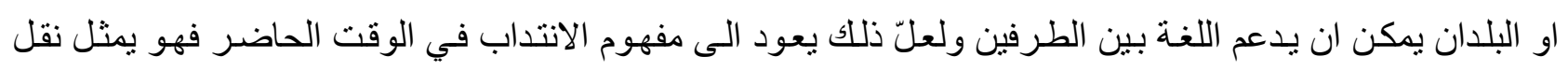
الحضارة او الثقافة الى الثعوب الفقيرة مثلما نجد في دول المغرب العربي من انتقال الكثير من صفات اللغنة الفرنسية

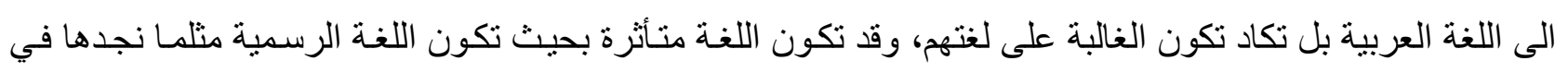
الكثير من الدول الاوربية والأسيوية التي تتازلت عن لغتها الرسمية واستبدلتها بلغة البلد المحتل كمـا في المستعمرات الاوربية ، فقد كانت اللاتينية قديما إحدى لغات الفرع الايطالي من مجموعة ( الهندو ـ أوربيـة ) محضرة في منطقة ضيقة مـن ايطاليـا واصبحت بعد انتصـار ها في الصـر اع لغـة رسمية لكل مـن : إيطاليـا، البرتغـال، أسبانيا ، الجـول (فرنسا)، و الألب و ألبانيا .

זـ التجاور الجغر افي واهمية ذلك من انتقال الكثير من الالفاظ والكلمات بين اللغات فضلا عن انتقال الصفات اللغويـة على مستوى الاصو ات و التر اكيب ، ويكمن ذلك في المستوى المتحضر لكل لغة ومدى تاثير ها في اللغـة الاخرى و هذا

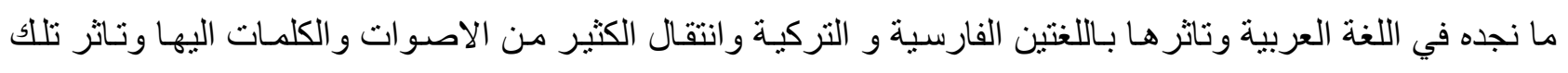


الاسبانية.

r- العلاقات الثقافية و العلمية والتجارية لها اثر كبير في التأثر و التأثير بين اللغات ، فقد أولت التجارة بين البلدان الى انتقال الصفات اللغوية و المفردات بين اللغات ، فقد ورد أنّ الاسبانية اقترضت من العربيـة اكثر من اربعمائة لفظلة ،

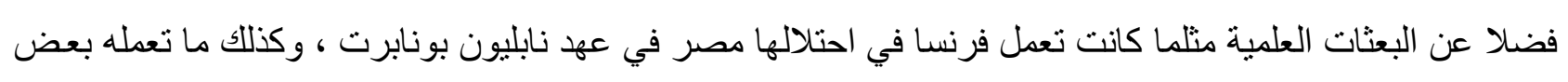



عـ الصر اع بين الحضار ات ، ويعود ذلك الى قدرة عر اقة كل منها في الثقافة و الحضـارة وقوة التاثير ، فنجد تنافسهما

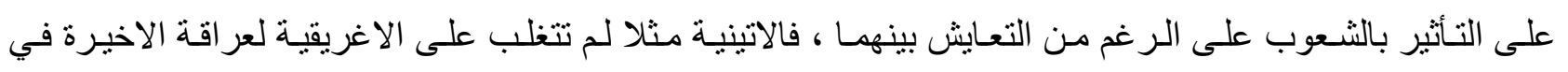

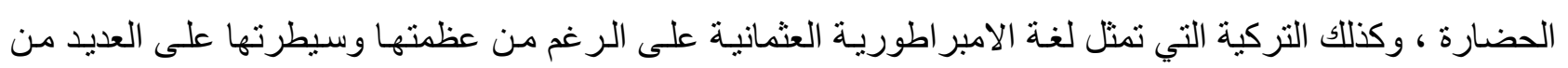


الدول العربية لم تستطع التنافس والتغلب على اللغـة الفرنسية أو اللغـة الأنكليزيـة التي أثرت على أبنـاء العربيـة ويعود ذلك الى حداثة الحضارة التركية وقصر المدة التي حكمو ا فيها. ولعلّ سمة التعايش بين اللغات يولد العديد من المفاهيم اللغوية كالاقتر اض و الدخيل و المعرب ، ومن ذلك نجد أنّ العربية ( السامية ) بخصائصها اللغويـة المتعددة وحضـارتها العريقة قد استطاعت ان تتداخل مع غيرها من اللغات حين احتكت و اتصلت بالامم المجاورة بسبب الحروب و والتجارة

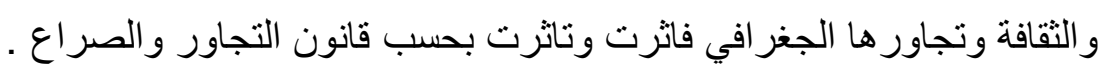

\section{- العربية والهندو- أوربية التأثير والتـأثر:}

تعد اللغات الهندو - أوربية من أكثر اللغات انتشـار اً في العـالم وأكثر هـا تداخلاً باللغـة العربية، فهي تمتد مـابين

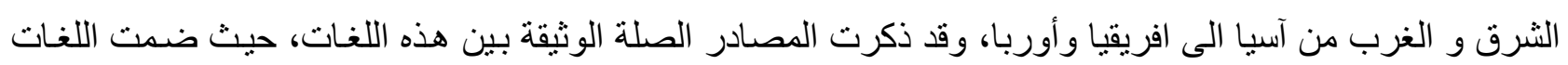



ا ـ اللغات الهندية الاير انية أو اللغات الآرية ، وتتشمل شعبتين :

الاولى: شعبة اللغات الهندية ( السنسكريتية البر اكيتية ، و اللغات الهندية الحديثة )

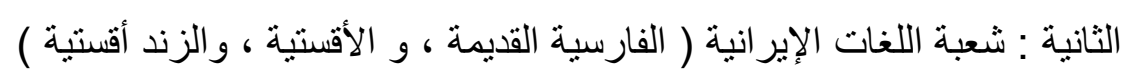
ب- اللغات الأرمينية .

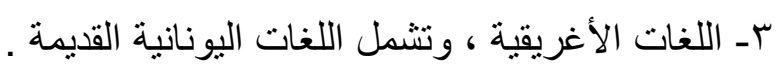
ـ - اللغات الألبانية .

الخ.لغات الإيطالية، وتثنمل الأسكية ، و الأمبرية السمنية و اللاتينية القديمة و اللغات الرومانية ، و اللغات المنتـعبة

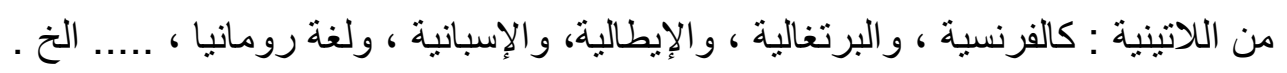
آـ اللغـات السـلتية القديمـة: ، وقد طغت عليها الآن اللغـات : الفرنسية و الإنكليزيـة والإسبانية ، ولكن بقي بعض أشكالها في كثير من اللهجات المحلية بايرلندا و ويلز ومنطقة البيرتون بغرب فرنسا . Vـ اللغـات الجرمانيـة، وتثـمل ثـلاث شعب : شعبة اللغـات الجرمانيـة الثـرقية ، و وهي اللغـة الجوتيـة ، وشعبة اللغـات الجرمانية الثمالية و هي لغات : ايسلندا و الدنمارك و السويد و النرويج ، وشعبة اللغات الجرمانية الغربيـة ، وتشمل :

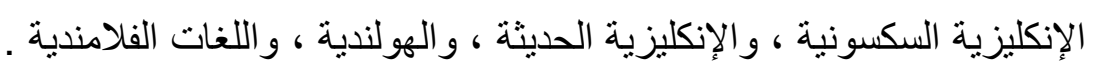

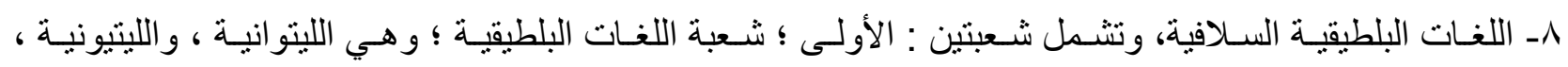

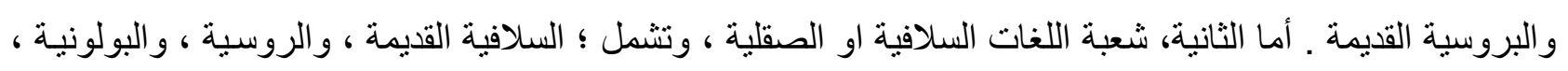



وسيقتصر الحديث على أبرز اللغات ضمن هذه العائلة اللغوية وأكثر ها نأثراً و تأثثيراً في العربية :

\section{ا- العربية والهندية القديمة:}

تمثل بلاد الهند حضارة عريقة امتدت لعشرات القرون ، فظهرت فيها أمم وشـوب وديانـات متعددة و لاز الت




الاحتلال على يبد البريطانيين ، فقد امتدت تلك الحقبة الى ما يقارب اربعة عقود ، وهي فترة لبست بالقليلة مدا اثّر في لغاتها العديدة حيث سادت اللغة الإنكليزية كلغة رسمية وبقيت لغاتها الأصل بمثابـة اللغات الثانويـة ، و المتتبع لحضـارة الهند القديمة وهو ما يعنينا في دراستنا يجد أنّ اللغـة السـائدة حينذاك هي اللغـة السنسكريتية ، وهي اللغـة الأم عندهم ، وقد ذكرت المصادر القديمة أنّ هناك مشتركات بين العربية والسنسكريتية القديمة ، فقد أعلن ( سير جون مارشـال ) أن أعو انه من الهنود قد اكتشفوا عند ( مو هنجو ـ دارو ) على الضفة الغربية من السند الاعلى دلائل على أنّ هذه المدينة كانت تتصل مع سومر وبابل بصـلات تجاريـة ودينيـة وفنيـة ، و أنّها ظلت قائمـة أكثر من ثناثثة آلاف عـام حتى القرن

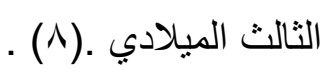

أمّا ما وطّّ العلاقات بين العربية و الهندية هي الرحلات التجارية بين البلدان العربيـة وشبه القارة الهنديـة ولا

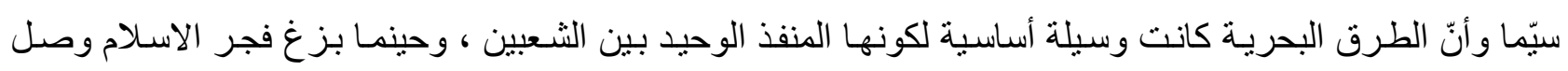
المسلمون الفاتحون الى الهند وإن كانت متأخرة بعض الثيء ، ففتجوا اجزاء كبيرة منها في عام الو هـ وسموها بـلاد ( السند ) فنقلوا الى العربية العلوم و المعارف و الاداب و الفلسفة وغير ها ، أما في مجال اللغة و الأدب ، فقد وصلت الينا


أمّا الألفاظ التي يعتقد قد أن أصولها عربية ، نذكر منها : كلمة موز فأصله في السنسكريتية القديمة ( Mucha ) ، وكلمة الصندل في السنسكريتية ( Chandan ) ، وكذلك كلمة فلفل في السنسكرينية ( pepale) ، أمّا الكلمـات التي انتقلت من اللغة الهندية إلى اللغـة العربية ، نذكر منها : البيغاء ، الزنجبيل ، الكافور ، الثطرنج ، الخيزران ... وغير ها ( ( ) . (1)

\section{r- العربية والفارسيية}

تعد اللغة الفارسية من اكثر اللغات التي اثرّت وتناثرت باللغـة العربيـة نتيجـة التجاور الجغرافي للبلدان العربيـة فضلا عن العلاقات التجارية والثقافية والعلمية والدينية بينهما ، ولم تكن هذه العلاقات حديثة العهد بل امتدت منذ فجر

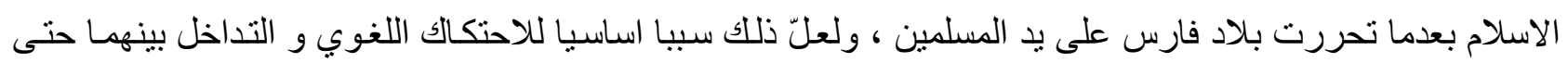
الوقت الحاضر ، غير انّ اللغة الفارسية القديمة وهي اللغة الفهلويـة التي امتدت حتى عصر الاحتجـاج تختلف اختلافاً

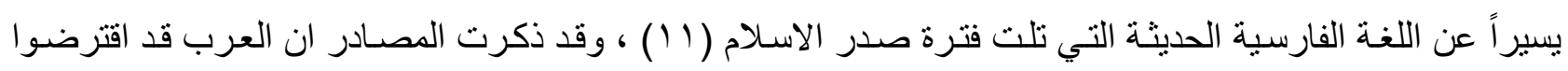

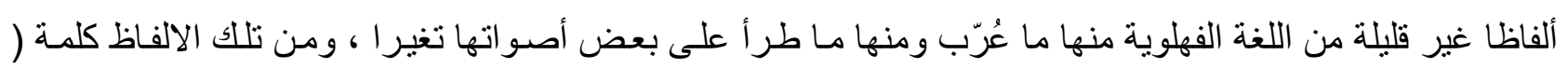


وكذلك كلمة ( مهندس) فقد وردت في الفهلوية ( هنداز ) أمـا الفارسية الحديثة فقد ذكرتها ( انداز ) ، ولعلّ مـا ورد بالصيغة ذاتها كلمة ( هندام ) التي ذكرتها اللغة الفهلوية بالمعنى ذاته لكنّ الفارسية الحديثة ذكرتها ( اندام ) باستبدال صوت الهاء بصوت الهمزة (Y) (I) .

أما الفارسية الحديثة فقد أدخلت على العربية الكثير من الألفاظ التي ذكرتها المصسادر القديمة والحديثة نذكر منها على سبيل المثال لا الحصر: "الياقوت، البلور، الابريق، الكوز، الابريس،، الاستبرق ، الكعلك، الجوز، اللوز، النرجس ، الدولاب، الخندق، الدستور، الثطرنج، التنور، الجاموس ، الديوان، العسكر ....."( I ) 
ونتيجـة امتزاج الثقافات بين اللغتين استطاعت العربيـة ان تتداخل مـع الفارسية في أغلب الالفاظ لا سيّما بعد دخول الاسـلام وتعلّم لغـة القر آن والأحاديث النبويـة و السيرة و غير هـا وهذا مـا جعل اللغـة و الأدب بفنونهمـا يمتزجـان

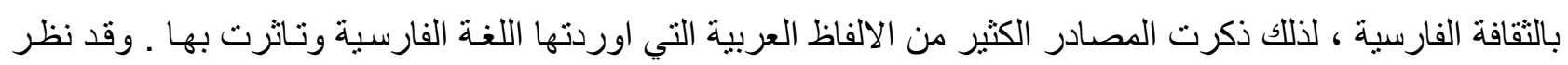

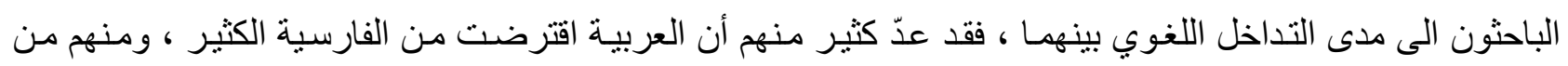
ذهب الى أبعد من ذلك حينما أثناروا بالأدلة بأنّ الفارسية هي من أقترضت الكثير من المفردات العربية سو اء أكان

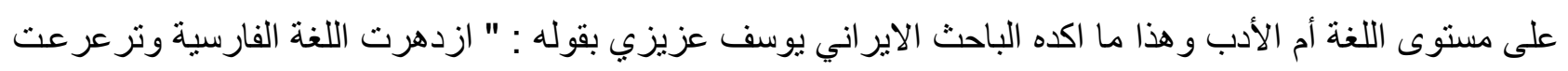
في أحضان الأبجدية العربية بعد القتح الاسلامي لإير ان ، وقدمت شعر اء ومتصوفين ومفكرين عظامـاً ، خلافاً لمـا قبل

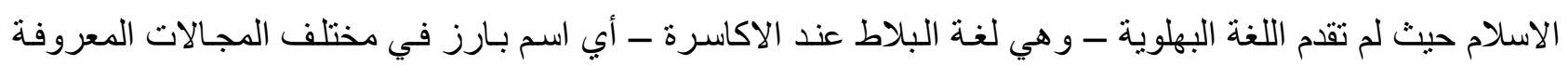
وخاصة الأدب ، ويبدو أن اللغة الفارسية استعارت من اللغـة العربية الكثير من ثر اكيبها ومفرداتها ، و لاحقاً استفادت من اللغة المغولية عند سيطرة الامبر اطورية المغولية ومن ثم التركية " ، ويضيف بعد ذلك قوله : " لقد أثرت الثقافة العربية في الثقافة الفارسية عبر العصور ، وكان للأدب العربي تحديداً تأثنير مهم في الادب الفارسي كما وكان للغنة العربية أيضاً دور في إغناء اللغة الفارسية بالمفردات المتعددة ، فهنالك نحو ، 7 \% من اللغة الفارسية مفردات عربية

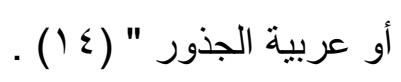

ولعلّ ما يمكن إجماله من سمات التداخل اللغوي بين العربية و الفارسية بوجه عام (1 ) :

ا ـ تعـد الكلمـات الدخيلـة مـن الفارسيالقديمة:المقارنة مـع الكلمـات العربيـة ، وذللك يعود الـى ضـعف سطوة الحضـارة

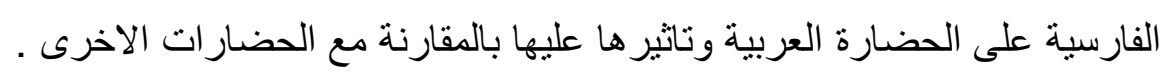
r- لم تتنوع الكلمات الفارسية في مجالات متعددة ، فكل ما دخل العربية بعض الاسماء و الصفات بخلاف الفارسية التي تاثرت بالعربية من خلال حروفها وفنونها الادبية . rـ لم تكن تللك الألفاظ او الكلمات في أغلبها على ما دخلت عليه انما قد يشتق منها افعالا كما في: كهرب، مغطس، ... . . عـ اخضاع اغلب الكلمات الى قو اعد العربية سواء في اصو اتها او قو اعدها الصرفية هـ استعار العرب من الفرس الفاظـا لها نظليائر في لغتهم ، ويعود ذلك امـا لخفتها او سعة اطـلاع العرب و واتصـالهم بالفرس .

\section{r- العربية واليونانية و اللاتينية القدبيمة:}

تعد اللغتان اليونانية واللاتينية القديمة من اللغات الهندو - اوربية التي كانت تسيطر ان بشكل كبير على أجزاء و واسعة من الثرق الاوسط بعد الاحتلال اليوناني والروماني في عهد فتوحات الاسكندر المقدوني (Tهب - ك كس ق.م) وما بعدها، فاليونانية موطنها الاصلي بلاد اليونان و اللاتينية لغة ايطاليا ، وتعد سوريا البلد العربي الأكثر تواصلاً

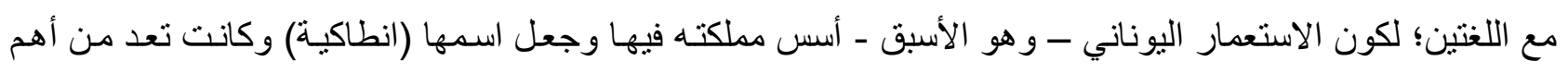

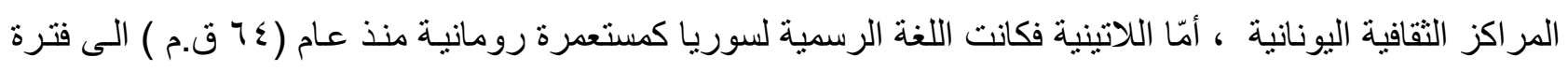
الفتح الاسلامي وسميت باللغـة الروميـة (7 (1)، ولعلّ تلك الأسباب جعل تأثنير اللغتين جلياً على اللغـة العربية و انتقال

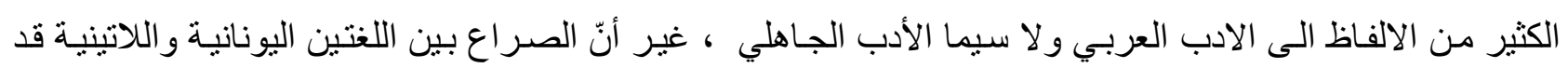


جعلهما يتأثر ان ببعضهما ، وقد أثرنا سابقاً أن من أسباب التأثثر والتأثر هو صراع الحضـار ات ، ولمـا كانت اليونانية اكثر ثقافة وحضارة استطاعت ان تؤثر على اللاتينية وتفرض لغتها ، و وعلى اثر الصـر اع اللغوي تو افدت الى العربيـة

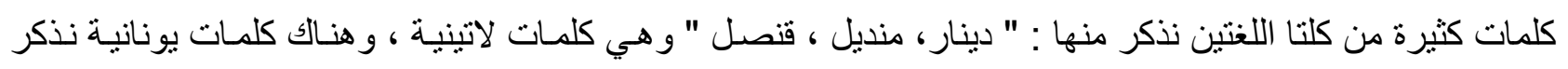

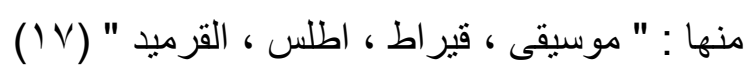

ويبدو أنّ نأثر اللغات اليونانية واللاتنية باللغة العربية اخذ حيّز اً كبيراً ، فقد وردت اشـار ات عديدة ذكرهـا الاب

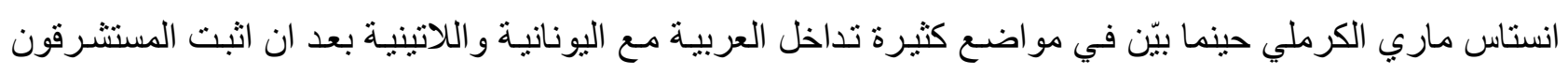
بأن "العربية من غير المعقول أن تتأثر أو نؤثر باللغات البعيدة عنها ، وقد ذكر الكرملي قوله :" قد وجدنا الشـابهات

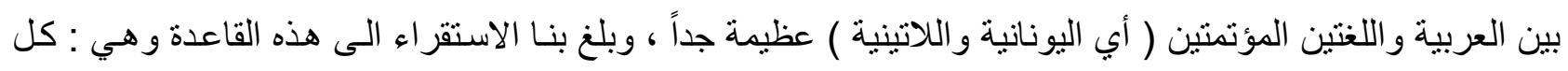
لفظة يونانية او لاتينية ذات هجاء اوحد او هجاءين ، فلا بد من ان يكون مقابل في المضرية ، وقد تتفق معاني اللفظتين

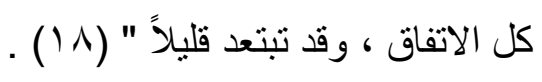

ومن الأمثلة التي ذكر ها الكرملي من باب التقابل اللغوي لفظة (البلّوطـة) في اللغنة اليونانية ( BALANOS )

، وقد وجد علماء اللغة الغربيون أنّ أقرب كلمة إلى هذه اللفظة في اللغة اللاتينية ( glaus )، فيما لاحظو المقابلات لها لهابه

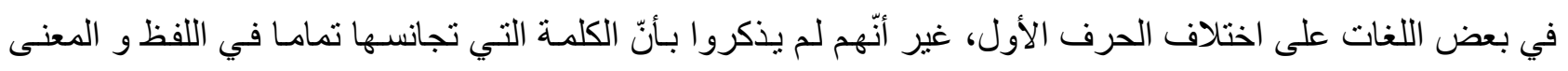


و اضح من حيث الثكل ، أما التقارب الصوتي ( النطقي ) بين اللفظتين يعود إلى الأصل اللغوي القديم للفظة هو (بَلان)

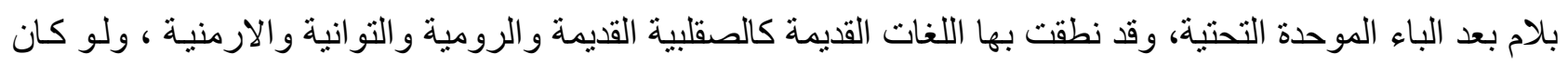
هنالك نص عربي قبل المسيح بألف سنة لسمعناهم يقولون ( بلان ) ؛ لأنّ قلب اللام نونا أو قلب النون لاماً كان مشـهورا

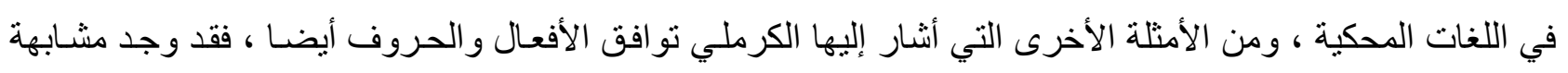
حرف الجواب ( نَعَم) باختلاف لغاته في العربية ، فقد ورد في اليونانية بلغات متعددة كان أبرزها ( NAI-MAN ) ،

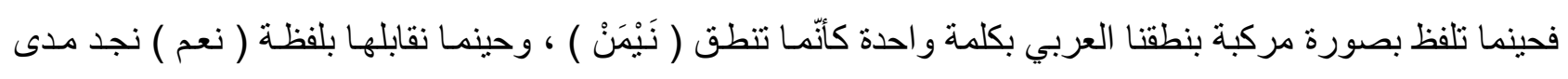

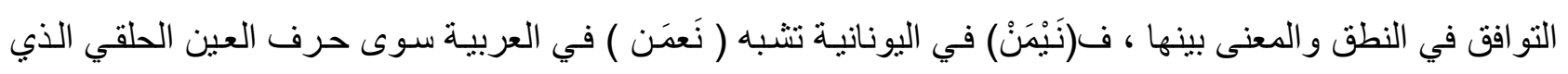
يسقط في لغات الغرب ، مثلما نجد بعض الاختلافات في بعض الحروف في اللهجات القديمة في العربية نفسـها (9 (1). وقد ذكر الأب رفائيل نخلة اليسوعي ما يقارب تسعين لفظة اقتبستها اليونانية من العربية (·r). أما اللاتينية فلا تكاد تختلف عن اليونانيـة في طبيعة تاثر هـا بالعربيـة، غير ان اليونانيـة اكثر تـاثر اً من اللاتينية

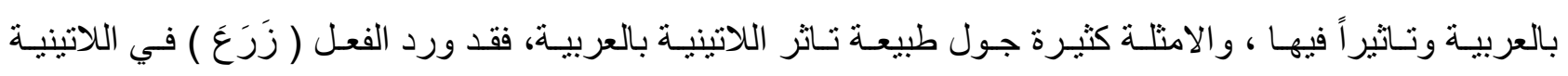

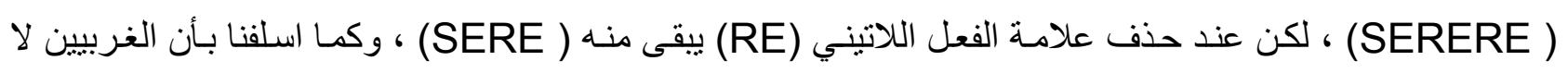
بنطقون احرف الحلق، فقد عوض عنها بالحرف (E)، فاصبحت تنطق ( سَرَى)، علما انّ صوت ( الزاب ) في العربية يلفظ في اللاتينية ( سيناً ) ـ وبذلك تو افقت اللفظتان نطقا ومعنى ـ ويبدو أنّ طبيعة الاشتقاق سمة اساسية في اصـالة اللغتين ، فاللاتينية حينما تولد كلمات مشتقة تختلف صياغتها من مشتق الى آخر ، و واختلاف المشتقات عن اصل الكلمـة على عكس العربية التي تبقي جذور الكلمة ( الاصل ) في مشتقاتها (الفروع)(Y (Y) . 
ولا تكتفي اللاتينيـة بالأسماء والأفعال في تأثرهـا بالعربيـة بـل تعدتها الى الحروف ، فقد وردت في الحروف

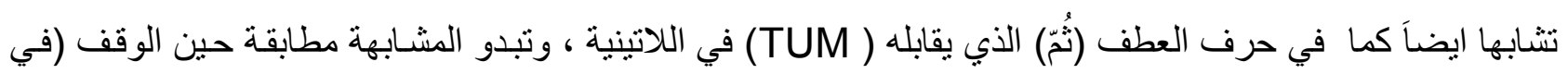
حالة العطف) لا في حالة الظرفية ، لأنّ هذه اللفظـة اللاتينيـة يمكن أن تكون ظرفاً بمعنى (حينئذ)، وبالتالي لا تتحقق المقابلة (Y (Y) (

وحقيقة ما لمسناه من أصالة العربية في تأثنير ها على اللغتين اليونانية واللاتينية يعود الى طبيعـة اصـول الكلمـات في كلتا اللغتين ، فهناك العشرات من الكلمات في معاجم اللغتين لا يعرف مصدر ها، وهذا مـا ورد في كلامهم ــ كما فيا

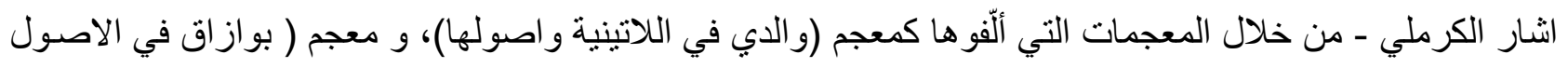

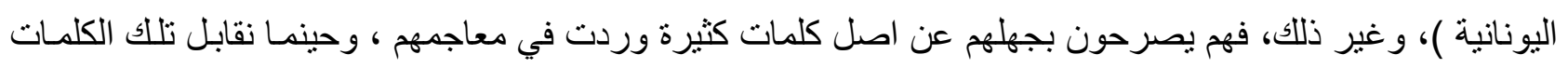
المجهولة نجد ان اللغة العربية احتفظت باصالة اللفظة ومعناها ، وهذا دليل على اصالة العربية .

ك- العربية هم الفرنسية والانكليرنية والاسبانية:

تتمتع العربية بميزات لعلّها تغلبت على باقي اللغات الاخرى بقوة نفوذهـا وسطوتها ، وسر عة انتقال الالفاظ

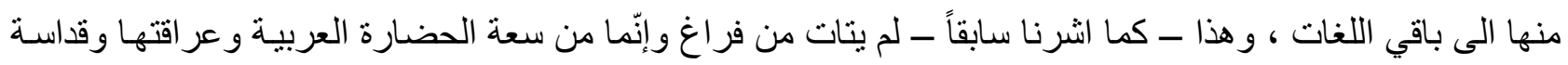
لغتها ، ولعلّ مـا جعل العربيـة تصل الى البلدان الاوربيـة هو قدرتها على التحرك بصورة اكبر لاسيّما بعد انتشــار

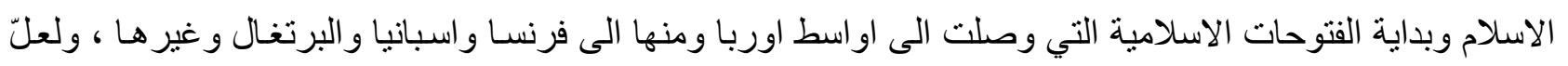
مـا جرى في فرنسـا على الرغم من وصـول المسلمين الى جزء منها و هي و لايـة صغيرة واقعـة على سـاحل البحر

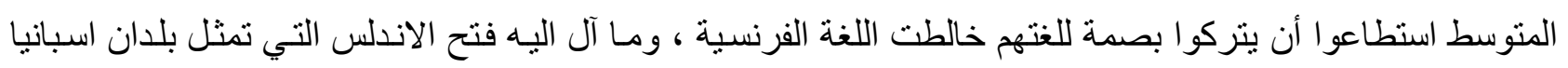
و البرتغال في الوقت الر اهن قد نقل ثقافة الاسلام ولغته ، فقد بلغت العربيـة أوجّها في تلك الحقبـة ، وهذا مـا ظهر في وهي

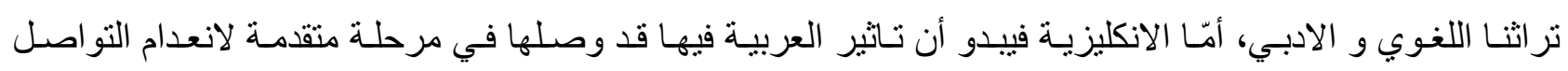
الجغر افي، فضلاً عن كون العرب الفـاتحين لم يصلوا اليها في تلك الحقبـة، لكن ذلك لا يعني أن الانكليزيـة لم تتأثر بالعربية، وإن كانت المدّة قليلة بالمقارنة مع غيرها من الامم الاوربية فقد أصبحت بالمرتبة الاولى بالنسبة الى العلاقة

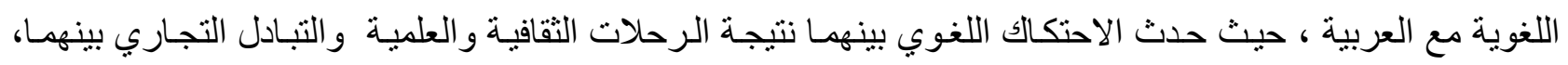
فضلاً عما تركه الاحتلال الانكليزي لاغلب البلدان العربيـة ، ويبدو أنّ الاهتمـام باللغـة العربيـة بدأ رسمياً حينمـا دعت



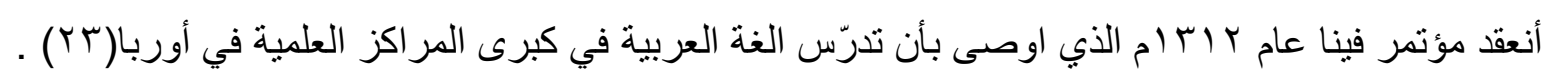


أما تأثر العربية باللغة الانكليزية فهو واسع ومتعدد في كثرة الالفاظ سواء المعربة او الاخيلة ،

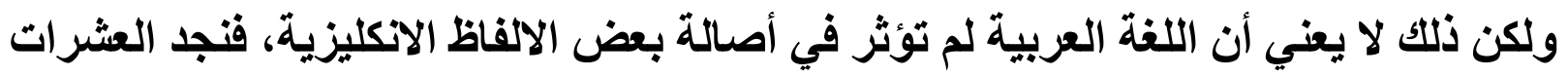

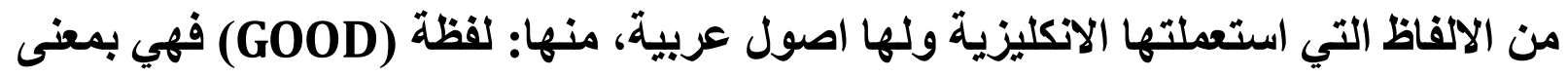

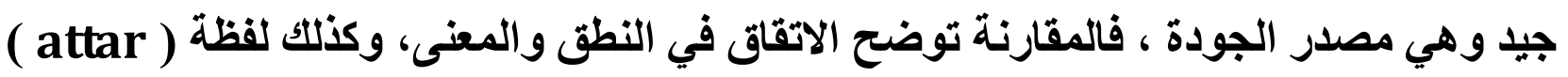
بمعنى عطر، ومنه مشتق عطار، وفيه مقاربة صريحة وكذلك في الألفاظ التالية:

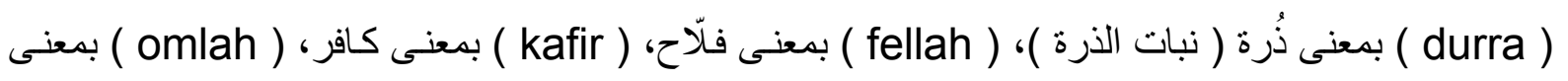

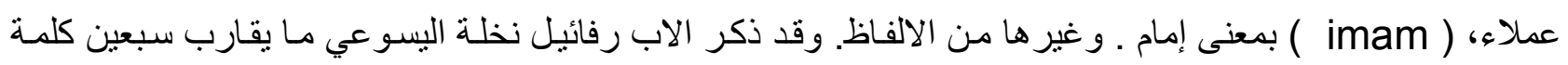
انكليزية لها أصل في العربية (ع ب).

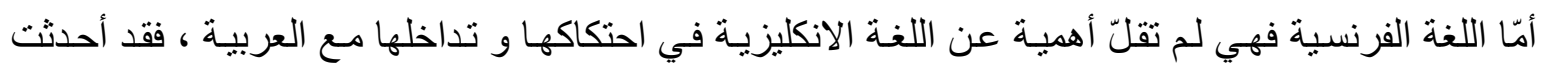

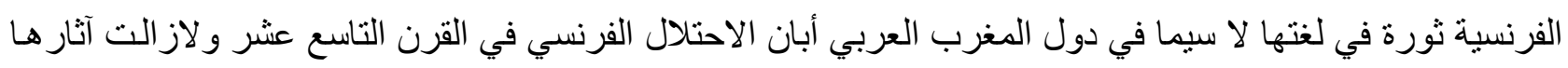

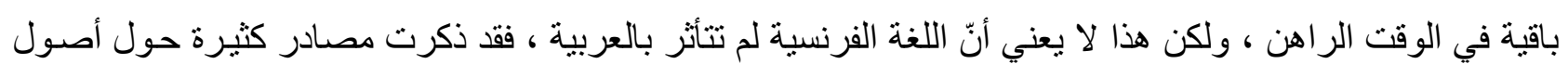

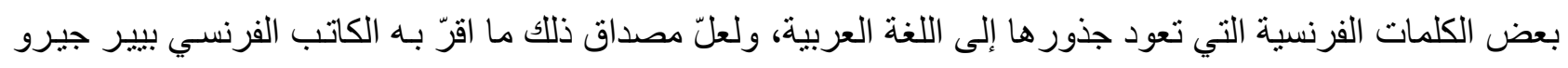



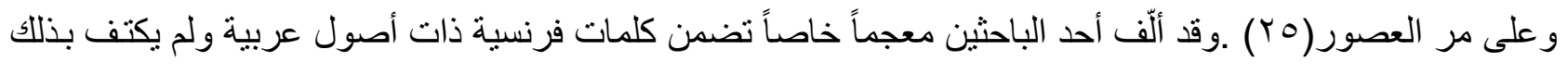

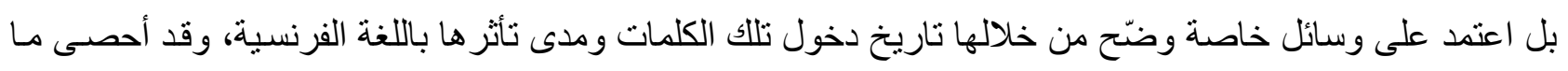

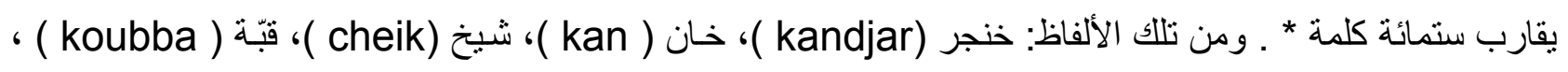
وغير ها.

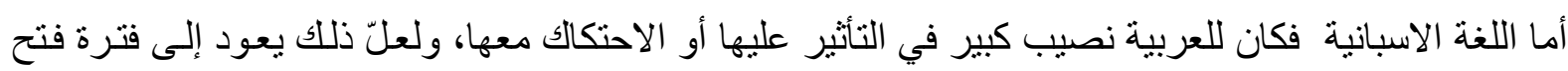

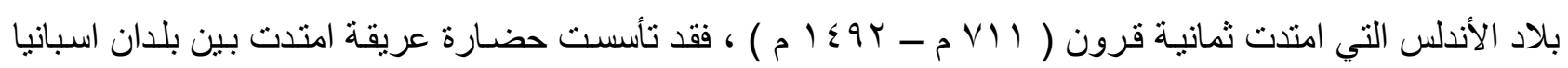



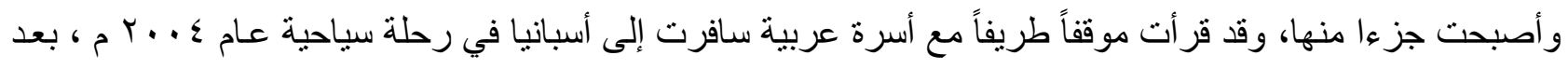

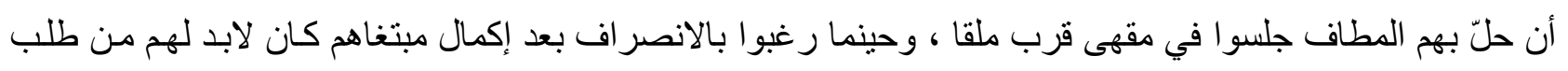

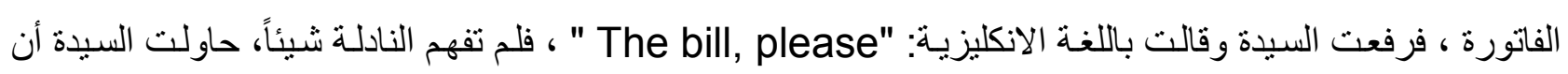

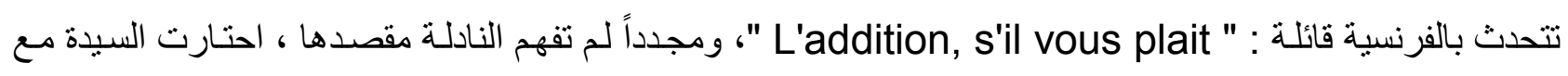

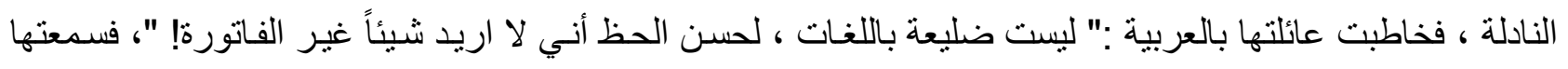

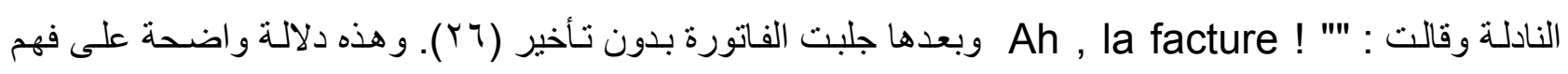

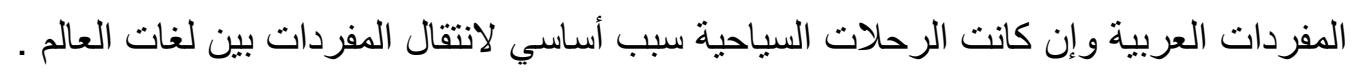

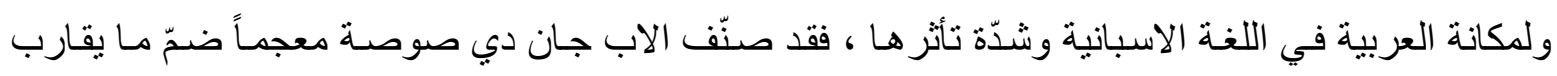

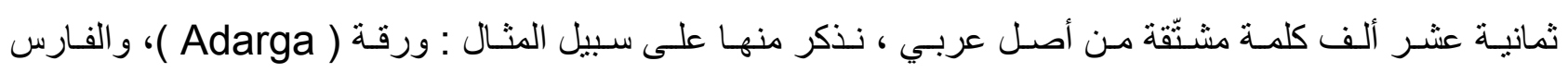

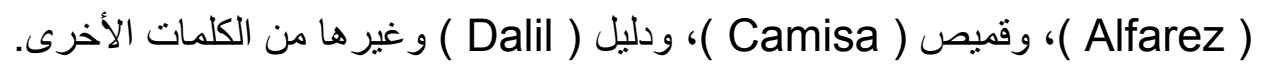




\section{الخاتمة}

بعد هذه الدر اسة المقتضبة عن علاقة العربية باللغات الهندو ــ أوربية ، يمكن أن نلحظ الجوانب التالية : يمثل التداخل اللغوي مظهراً من مظاهر التطور اللغوي ، وقد حققت العربية الصدارة في ذلك .

- - يُعد التأثير والتأثر بين اللغات قانوناً اجتماعيا يكثف عن مدى التواصل بين اللغـات ، وكثف الروابط الأدبية و الثقافية بينهما ، على الرغم من تعدد عو امله وأسبابه .

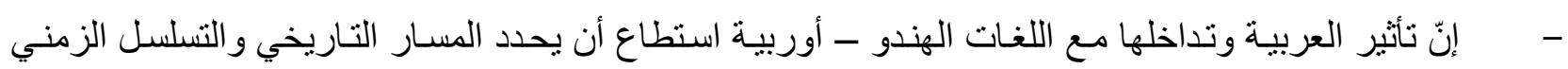
لتلك اللغات ، فضلاً عن أسباب نشأتها وطبيعة تحو لاتها الصوتية والتركيبية .

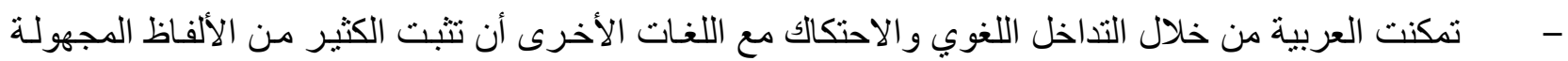
في المعجمات اللغوية لتلك اللغات .

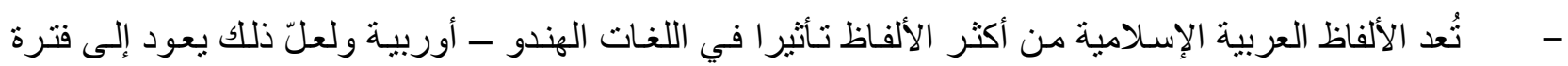

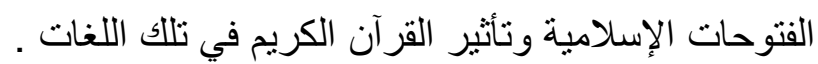

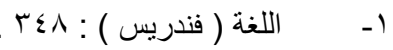

*ـ الهنستانية : هي لغة الهند الثمالية ، حيث بتكلم بها خمسة و عشرون مليوناً من المسلمين ، فضلاً عن عدّة ملايين غير هم الى جانب لغاتهم الخاصة .



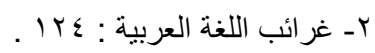

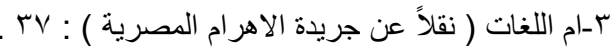

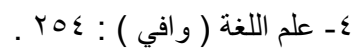
๑- ينظر : مجلة اللسان العربي : العدد الخامس / / 19 ـ . .

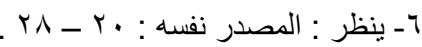

*ـ تخصص بريطانيا ميز انية سنوية تقدر بمائتي مليون جنيه استرليني لنشر اللغة الانكليزية عن طريق دعم المر اكز البريطانية فضلا عن برامج تعليم

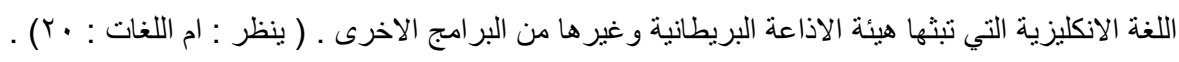

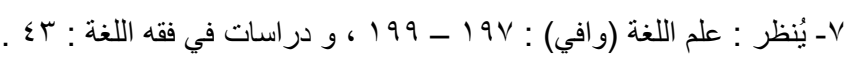

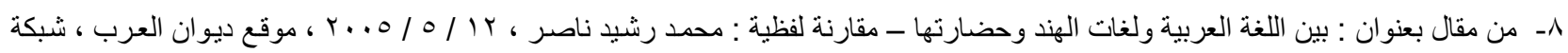
الانترنت .

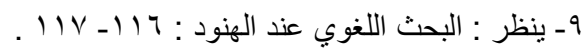

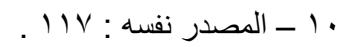



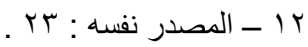
rا 1 - يُنظر: فقه اللغة واسرار العربية : 191 ـ 99 19، والألفاظ الفارسية المعربة: 10

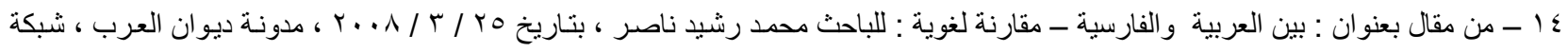
الانترنيت .

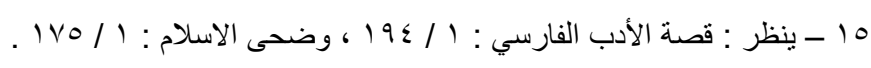

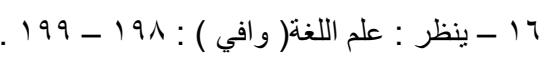
IV 


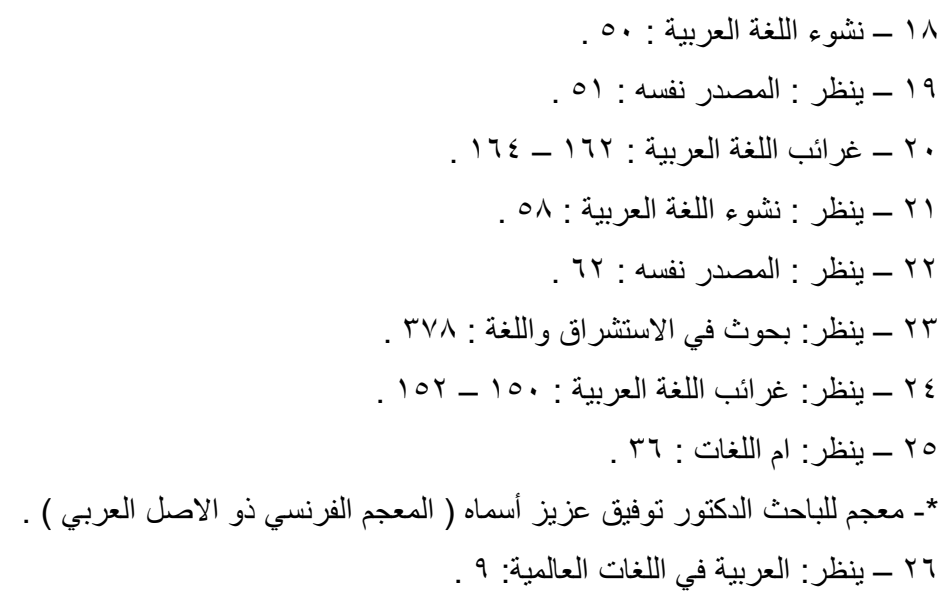

المادر و المراجع

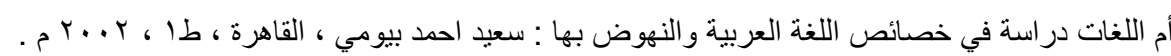

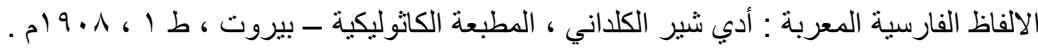

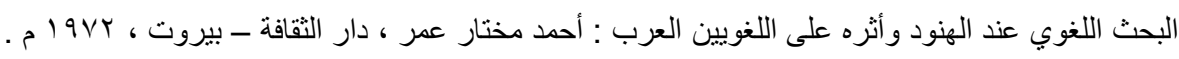





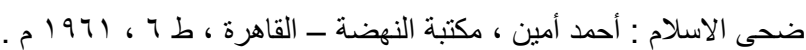

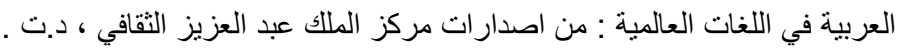

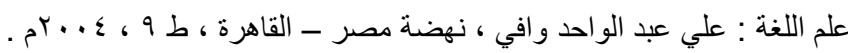

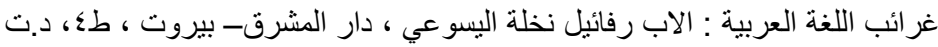

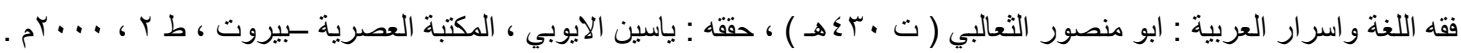

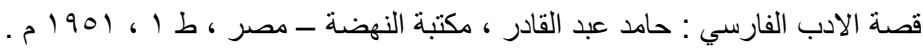

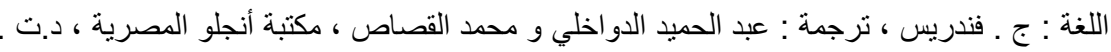





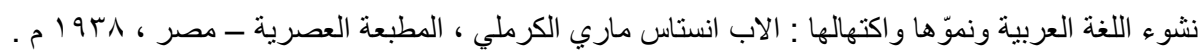

